\title{
FLOW AND THERMAL PROPERTIES OF STEVIA POWDER
}

\author{
Ajit K. MAHAPATRA*, Agnes J. KAPSOIYO, Sierra C. BIRMINGHAM, Daniel EKEFRE, Bipul K. BISWAS \\ College of Agriculture, Family Sciences and Technology, Fort Valley State University, Fort Valley, USA
}

\begin{abstract}
Stevia (Stevia rebaudiana Bertoni) has recently received a lot of attention as a sweetener due to its taste and low calorific value. Flow and thermal properties of foods play a significant role in the quantitative analysis of unit operations in the food industry. However, there are no published data available on flow and thermal properties of stevia powder. Powder Flow Tester and KD2 Pro Thermal Properties Analyzer were used to determine the flow and thermal properties of stevia powder, respectively, at different moisture contents (4.96\%, 9.68\%, 13.99\%, 20.08\%, and 25.79\%, w.b.). Mean angle of internal friction of stevia powder ranged from $41.13^{\circ}$ to $46.3^{\circ}$. The mean effective angle of internal friction ranged from $47.8^{\circ}$ to $52.5^{\circ}$ and the mean flow index ranged from 0.27 to 0.48 . Mean thermal conductivity of stevia powder ranged from $0.091 \mathrm{~W} \cdot \mathrm{m}^{-2} \cdot \mathrm{K}^{-1}$ to $0.115 \mathrm{~W} \cdot \mathrm{m}^{-2} \cdot \mathrm{K}^{-1}$. Mean thermal diffusivity ranged from $0.103 \mathrm{~mm}^{2} \cdot \mathrm{s}^{-1}$ to $0.121 \mathrm{~mm}^{2} \cdot \mathrm{s}^{-1}$ and mean volumetric specific heat ranged from $0.865 \mathrm{MJ} \cdot \mathrm{m}^{-3} \cdot \mathrm{K}^{-1}$ to $1.019 \mathrm{MJ} \cdot \mathrm{m}^{-3} \cdot \mathrm{K}^{-1}$. Polynomial regression models were developed to predict flow and thermal properties of stevia powder using moisture content of stevia powder.
\end{abstract}

Keywords: food properties; food processing and storage; food engineering; stevioside; rebaudioside A

Stevia (Stevia rebaudiana Bertoni) is a branched bushy shrub belonging to the Asteraceae family and is native to the north eastern part of Paraguay (Lasekan and Naidu, 2013; Lemus-Mondaca et al., 2012). Rebaudiana and phlebophylla are the only two species that produce steviol glycosides among the 230 species of Stevia genus (Brandle and Telmer, 2007). Stevia and stevioside have been used as substitutes for saccharine for the treatment of diabetes mellitus, obesity, and hypertension and also for the prevention of caries (Pól et al., 2007). Stevioside and rebaudiana A are the two major sweetening agents that are thermostable up to $200{ }^{\circ} \mathrm{C}$ and are suitable for use in cooked foods (Lemus-Mondaca et al., 2012). Stevioside, a white crystalline and odorless powder, which is almost 300 times sweeter than sucrose is extracted from the leaves of S. rebaudiana Bertoni (Gasmalla et al., 2014). Rebaudioside $A$ is about 250 to 400 times sweeter than sucrose and has a wide range of food applications (Flavia et al., 2007). In addition, stevia leaves are also a good source of carbohydrates (Gasmalla et al., 2014).

Powder flow properties are essential in handling and processing of food powders primarily related to the flow from hoppers and silos, mixing, transportation, compression, and packaging (Fitzpatrick et al., 2004; Slettengren et al., 2016). The ability of a powder to flow depends on its physical properties (size, density, and surface area), moisture content, and types of equipment used during handling, processing and storage. The moisture content of a powder plays a significant role in its flowability as the liquid bridges and capillary forces acting between powder particles lead to reduced flowability (de Campos and do Carmo Ferreira, 2013).
Thermal processes such as drying, heating, cooling, sterilization, cooking, and refrigeration are commonly used in food processing, transportation and preservation operations. Thermal conductivity, thermal diffusivity and specific heat are three important engineering properties of a food material related to heat transfer characteristics (Božiková et al., 2015). Hence, the response of stevia powder to heat transfer is dependent on these properties. Knowledge of thermal properties of stevia powder is important not only for designing optimal processing systems and developing equipment for drying, but also for the prediction and control of various changes occurring in stevia powder during thermal processing and storage. The objective of this research was to determine the flow and thermal properties of stevia powder and evaluate the effect of moisture content on those properties.

\section{Material and methods}

\section{Sample preparation}

Stevia plants were harvested from the Fort Valley State University research field, put in brown harvesting paper bags and dried at $60{ }^{\circ} \mathrm{C}$ in a convection oven (Thermal Product Solutions, White Deer, PA) for $72 \mathrm{~h}$. Leaves were separated from the twigs and further ground to fine powder with a Thomas-Wiley laboratory mill (Model 4, Arthur H. Thomas Company, Philadelphia, PA). Fine powder was packed into Ziploc bags, sealed tightly and stored in a refrigerator at $4{ }^{\circ} \mathrm{C}$ (VWR, Model GDM-47, True Manufacturing, Inc., O'fallon, $\mathrm{MO})$. Assessment of the effect of moisture content on flow 
and thermal properties of stevia powder was conducted at five levels of moisture contents (4.96\%, 9.68\%, 13.99\%, $20.08 \%$, and $25.79 \%$, w.b.). Moisture content of stevia powder was determined in triplicates according to the ASABE Standard S358.2 (ASABE, 2011) by drying in an oven at $103{ }^{\circ} \mathrm{C}$ for $24 \mathrm{~h}$. The initial moisture content of stevia powder was $9.68 \%$. The samples at moisture contents above $9.68 \%$ and below $9.68 \%$ were prepared following the procedures described in previous work (Mahapatra et al., $2011,2013,2017)$. Bulk density was calculated by dividing the sample weight by sample volume (10 replicates at each moisture content, $n=10$ ).

\section{Flow properties measurement}

A Powder Flow Tester (PFT) (Brookfield Engineering Laboratories, Inc., Middleborough, MA) was used to determine the flow properties of stevia powder. The PFT uses the annular and Jenike shear tests techniques and is in compliance with the ASTM D6128 test procedures (Slettengren et al., 2016). Flow function tests were conducted using a vane lid and running standard flow function test program (max. stress: $4.82 \mathrm{kPa}$; no. of consolidation levels: 5; no. of stresses: 3 ; axial speed: $1.0 \mathrm{~mm} \cdot \mathrm{s}^{-1}$; flow index stress: $10 \mathrm{kPa}$; arching flow factor: 1.40). Software provided by PFT manufacturer automatically calculated the following: cohesion; angle of internal friction; effective angle of internal friction, and flow index.

\section{Thermal properties measurement}

Thermal properties of stevia powder were measured using a KD2 Pro Thermal Properties Analyzer (Decagon Devices, Inc., Pullman, WA) as described by Mahapatra et al. (2017). Thermal properties were measured in triplicate and repeated 10 times $(n=30)$.

\section{Statistical analysis and modeling procedures}

Flow and thermal properties were measured at five moisture contents and the mean values were calculated at each moisture content. Data were analyzed using the general linear models (GLM) procedures of the Statistical Analysis System (Version 9.4, SAS Institute Inc., Cary, NC) and the least significant difference (LSD) among means was calculated at $5 \%$ significant level $(p<0.05)$. Regression techniques were used to assess the relationship between moisture content and both the properties. Second degree polynomial models were developed using PROC REG (regression procedure) and GLM (general linear models) procedures of SAS. Five statistical indices including correlation coefficient $(R)$, mean relative percentage residual (MRPR), bias factor, accuracy factor, and root mean square residual (RMSR) were calculated to assess performance of the models (Gosukonda et al., 2017; Jeyamkondan et al., 2001). Measured and predicted values were averaged for plotting the graphs.

\section{Results and discussion}

Flow and thermal properties of stevia powder were determined at different moisture contents $(4.96 \%, 9.68 \%$, $13.99 \%, 20.08 \%$, and $25.79 \%$, w.b.). Mean room temperature recorded was $23 \pm 2{ }^{\circ} \mathrm{C}$. Mean bulk density of stevia powder ranged from $302.66 \pm 8.09$ to $375.53 \pm 5.47 \mathrm{~kg} \cdot \mathrm{m}^{-3}$.

\section{Flow properties of stevia powder}

\section{Cohesion}

Mean cohesion of stevia powder ranged from 0 to 0.012 \pm 0.008 . Cohesion in a powder is the result of either interparticle forces (electrostatic, moisture) or mechanical interlocking between adjacent particles. Moisture content increase results in increased distance between stevia powder particles, reduced electrostatic and molecular interactions, and, therefore, lower cohesion. Cohesion tends to decrease at moisture content heading towards the liquid limit and increases towards the shrinkage limit. Stevia powder indicated zero cohesion above $14 \%$ moisture content with an angle of internal friction ranging from 44 to $46^{\circ}$ (Table 1).

\section{Angle of internal friction}

Mean angle of internal friction of stevia powder ranged from $41.13 \pm 0.45^{\circ}$ to $45.83 \pm 1.09^{\circ}$ (Fig. 1 , Table 1 ) and was significantly ( $p<0.0001, R^{2}=0.77$ ) affected by moisture content. Increasing the moisture content of stevia powder from 5 to $14 \%$ increased the angle of internal friction by $8.4 \%$. However, for moisture content above $14 \%$, the value of angle of internal friction remained flat or decreased slightly with increasing moisture content (Fig. 1). Kamath et al. (1993) reported lower value of angle of internal friction for sugar $\left(31.3\right.$ to $\left.34.6^{\circ}\right)$. Fitzpatrick et al. (2004) reported the angle of internal friction for 13 food powders that varied from 42 to $65^{\circ}$. The measured values for angle of internal friction of stevia powder at all moisture content levels were greater than the critical value of less than $30^{\circ}$, hence, gravity discharge cannot be used to unload stevia powder from storage bins and silos (Fasina, 2006; Puri, 2002).

Table 1 Flow properties of stevia powder (mean $\pm \mathrm{SD}, n=3$ )

\begin{tabular}{|l||c|c|c|}
\hline $\begin{array}{l}\text { Moisture content, } \\
\text { w.b. (\%) }\end{array}$ & $\begin{array}{c}\text { Angle of internal } \\
\left.\text { friction } \mathbf{(}^{\circ}\right)\end{array}$ & $\begin{array}{c}\text { Effective angle } \\
\text { of internal friction } \mathbf{(}^{\circ}\end{array}$ & $\begin{array}{c}\text { Cohesion } \\
\text { (kPa) }\end{array}$ \\
\hline \hline $\mathbf{4 . 9 6}$ & $41.13 \pm 0.45 \mathrm{c}$ & $47.80 \pm 2.17 \mathrm{a}$ & $0.002 \pm 0.003 \mathrm{~b}$ \\
\hline $\mathbf{9 . 6 8}$ & $42.10 \pm 0.10 \mathrm{c}$ & $51.87 \pm 1.11 \mathrm{a}$ & $0.012 \pm 0.008 \mathrm{a}$ \\
\hline $\mathbf{1 3 . 9 9}$ & $44.60 \pm 0.27 \mathrm{a}, \mathrm{b}$ & $52.30 \pm 2.46 \mathrm{a}$ & 0 \\
\hline $\mathbf{2 0 . 0 8}$ & $45.83 \pm 1.09 \mathrm{a}$ & $52.50 \pm 2.86 \mathrm{a}$ & $0.30 \pm 0.01 \mathrm{~b}$ \\
\hline $\mathbf{2 5 . 7 9}$ & $44.13 \pm 0.51 \mathrm{~b}$ & $47.67 \pm 2.52 \mathrm{a}$ & $0.47 \pm 0.02 \mathrm{a}$ \\
\hline
\end{tabular}

Values in the same column with different letter are significantly different $(p<0.05)$ 


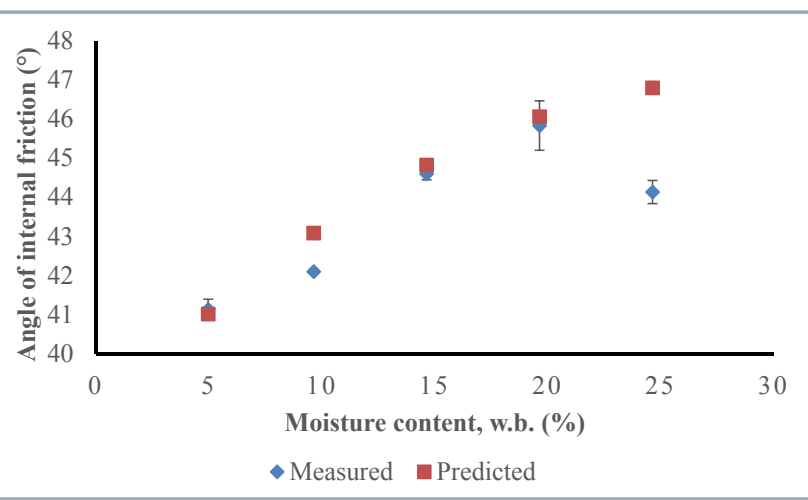

Fig. 1 Measured and predicted angle of internal friction of stevia powder

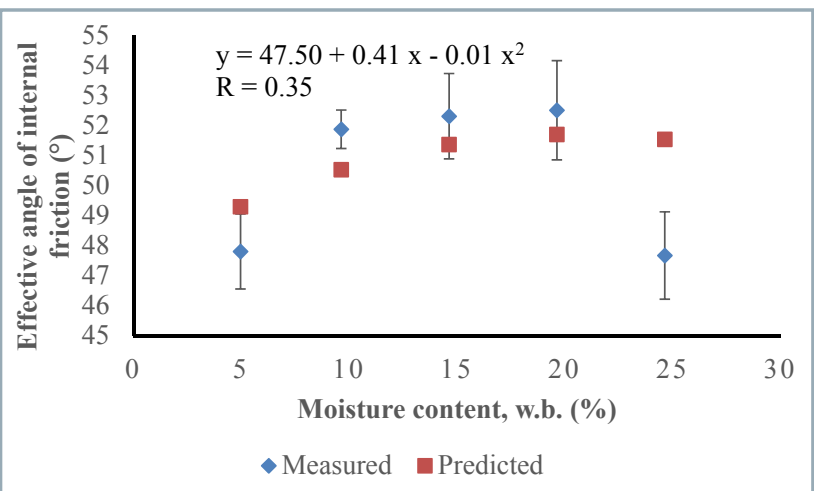

Fig. 2 Measured and predicted effective angle of internal friction of stevia powder

\section{Effective angle of internal friction}

The effective angle of internal friction of stevia powder, a measure of inter-particle interactions, were in the range of $47.8 \pm 2.2^{\circ}$ to $52.3 \pm 2.5^{\circ}$ (Fig. 2, Table 1). Statistical analysis of data showed that moisture content did not significantly ( $p=0.32, R^{2}=0.14$ ) affect the effective angle of internal friction.

\section{Flow index}

Mean flow index values of stevia powder were in the range of $0.27 \pm 0.01$ to $0.48 \pm 0.05$ (Fig. 3, Table 1) and were significantly $p<0.0001, R^{2}=0.83$ ) affected by moisture content. Increasing the moisture content of stevia powder from 5 to $26 \%$ increased the flow index by $78 \%$. From the flow index values, stevia powder can be classified as cohesive material (difficult to flow) and, therefore, low aids will be needed during discharging of stevia powder from storage bins, silos, and hoppers. Poor flowability of stevia powder could be due to particle shape, small particle size, and wider particle size distribution.

\section{Thermal properties of stevia powder}

\section{Thermal conductivity}

Mean thermal conductivity values of stevia powder ranged from $0.0910 \pm 0.0095$ to $0.1150 \pm 0.0146 \mathrm{~W} \cdot \mathrm{m}^{-1} \cdot \mathrm{K}^{-1}$ (Fig. 4, Table 2). Carson (2015) reported that thermal conductivity of particulate foods should range between 0.03 and 0.30 $\mathrm{W} \cdot \mathrm{m}^{-1} \cdot \mathrm{K}^{-1}$. Statistical analysis indicated that moisture content

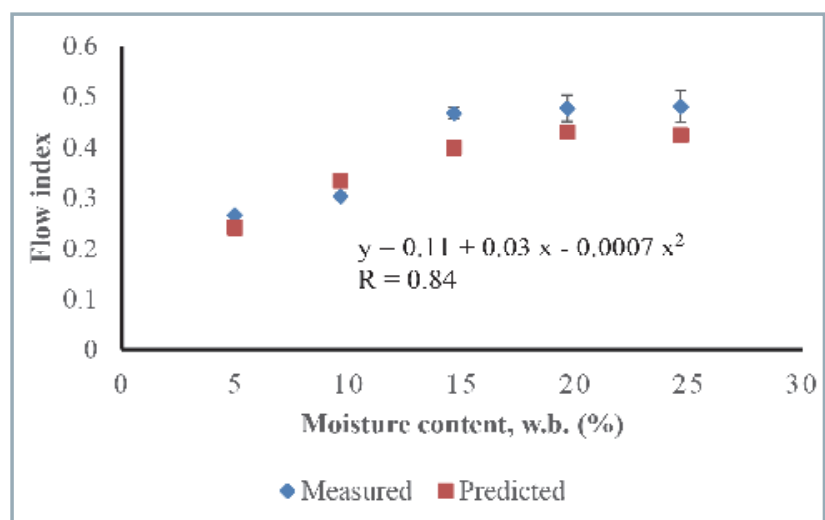

Fig. 3 Measured and predicted flow index of stevia powder

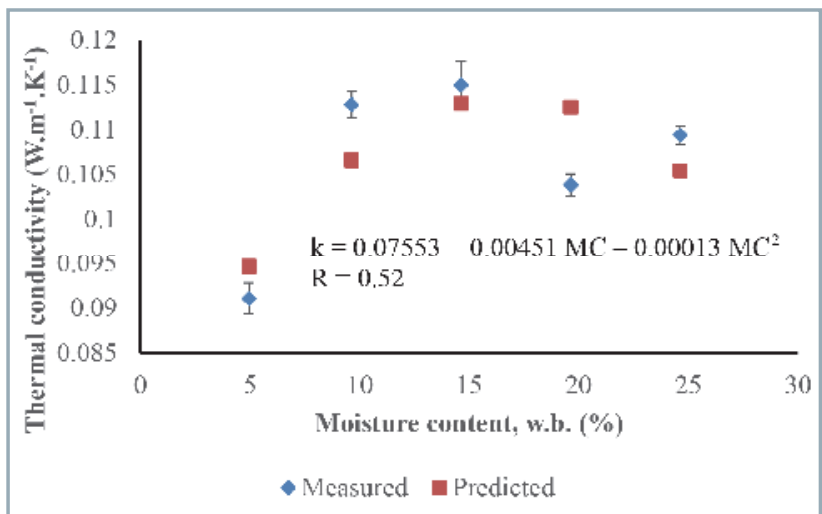

Fig. 4 Measured and predicted thermal conductivity of stevia powder

had a significant $(p<0.0001)$ effect on thermal conductivity values. The lowest thermal conductivity was obtained at moisture content of $5 \%$ and the highest value was obtained at moisture content of $14 \%$. Thermal conductivity increased with increase in moisture content from 5 to $14 \%$, but above $14 \%$ moisture content, thermal conductivity remained about constant or decreased slightly with increasing moisture content.

\section{Thermal diffusivity}

Thermal diffusivity of stevia powder ranged from $0.1032 \pm$ 0.0087 to $0.1206 \pm 0.0097 \mathrm{~mm}^{2} \cdot \mathrm{s}^{-1}$ (Fig. 5, Table 2). Statistical analysis indicated that moisture content had a significant $(p<0.0001)$ effect on thermal diffusivity values of stevia powder. The lowest thermal diffusivity was obtained at moisture content of $5 \%$ and the highest value was obtained at moisture content of $20 \%$. The thermal diffusivity increased with increase in moisture content up to a peak at $20 \%$. Further increase beyond this level resulted in a decrease in thermal diffusivity (Fig. 5). As moisture content of stevia powder increased, the pores and capillaries of stevia powder that were initially filled with air were gradually filled up by absorbing water. Heat released due to water adsorption in stevia powder resulted in the increased thermal diffusivity (Kostaropoulos and Saravacos, 1997; Raigar and Mishra, 2015). For most food and agricultural products, thermal diffusivity values range from 0.1 to $2.0 \times 10^{-7} \mathrm{~m}^{2} \cdot \mathrm{s}^{-1}$ (Huang and Liu, 2009). 
Table 2 Thermal properties of stevia powder (mean $\pm S D, n=30$ )

\begin{tabular}{|l|c|c|c|}
\hline \multirow{2}{*}{ Moisture content, w.b. (\%) } & \multicolumn{2}{|c|}{ Thermal properties } \\
\cline { 2 - 4 } & $\begin{array}{c}\text { thermal conductivity } \\
\left(\mathbf{W} \cdot \mathbf{m}^{-1} \cdot \mathbf{K}^{-\mathbf{1}} \mathbf{)}\right.\end{array}$ & thermal diffusivity $\left(\mathbf{m m}^{\mathbf{2}} \cdot \mathbf{s}^{-\mathbf{1}}\right)$ & specific heat $\left(\mathbf{M J} \cdot \mathbf{m}^{-\mathbf{3}} \cdot \mathbf{K}^{\mathbf{- 1}}\right)$ \\
\hline \hline $\mathbf{4 . 9 6}$ & $0.091 \pm 0.009 \mathrm{c}$ & $0.103 \pm 0.009 \mathrm{c}$ & $0.908 \pm 0.071 \mathrm{~b}$ \\
\hline $\mathbf{9 . 6 8}$ & $0.113 \pm 0.008 \mathrm{a}$ & $0.111 \pm 0.008 \mathrm{~b}$ & $1.019 \pm 0.044 \mathrm{a}$ \\
\hline $\mathbf{1 3 . 9 9}$ & $0.115 \pm 0.015 \mathrm{a}$ & $0.116 \pm 0.012 \mathrm{a}, \mathrm{b}$ & $0.988 \pm 0.054 \mathrm{a}$ \\
\hline $\mathbf{2 0 . 0 8}$ & $0.104 \pm 0.007 \mathrm{~b}$ & $0.121 \pm 0.009 \mathrm{a}$ & $0.865 \pm 0.044 \mathrm{~b}$ \\
\hline $\mathbf{2 5 . 7 9}$ & $0.109 \pm 0.006 \mathrm{a}, \mathrm{b}$ & $0.110 \pm 0.003 \mathrm{~b}$ & $0.958 \pm 0.185 \mathrm{a}$ \\
\hline
\end{tabular}

Values in the same column with different letter are significantly different $(p<0.05)$

Table 3 Selected statistical indices of polynomial regression models

\begin{tabular}{|l|c|c|c|c|}
\hline Flow and thermal properties & MRPR (\%) & Bias factor & Accuracy factor & RMSR \\
\hline Angle of internal friction & -1.82 & 1.02 & 1.02 & 1.37 \\
\hline Angle of effective internal friction & -1.20 & 1.01 & 1.05 & 2.76 \\
\hline Flow index & 6.78 & 0.93 & 1.12 & 0.06 \\
\hline Thermal conductivity & -0.99 & 1.01 & 1.07 & 0.01 \\
\hline Thermal diffusivity & -0.55 & 1.00 & 1.05 & 0.01 \\
\hline Volumetric specific heat & -0.66 & 1.00 & 1.07 & 0.08 \\
\hline
\end{tabular}

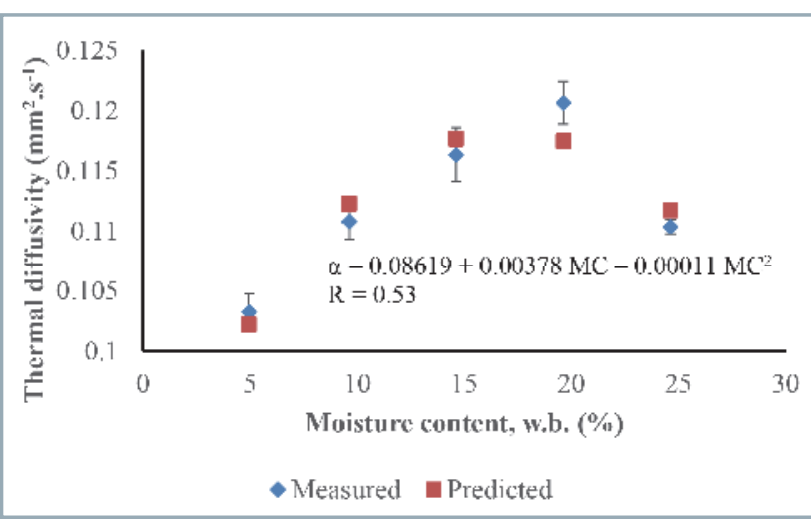

Fig. 5 Measured and predicted thermal diffusivity of stevia powder

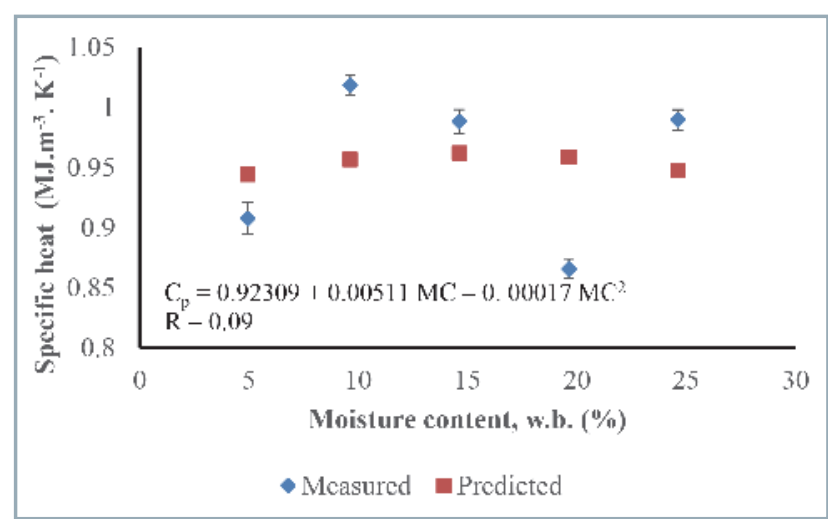

Fig. 6 Measured and predicted specific heat of stevia powder

\section{Specific heat}

Specific heat of stevia powder ranged from $0.8654 \pm 0.0436$ to $1.0185 \pm 0.0445 \mathrm{MJ} \cdot \mathrm{m}^{-3} \cdot \mathrm{K}^{-1}$ (Table 2). Statistical analysis indicated that moisture content had no significant $(p=0.26)$ effect on specific heat values of stevia powder. It can also be seen from Fig. 6 that the specific heat is independent of moisture content in the range studied and did not show any specific trend with moisture content.

\section{Performance of polynomial models}

Table 3 shows the selected statistical indices. The MRPR values indicate that models have over-predicted angle of internal friction (1.8\%) and angle of effective internal friction (1.2\%), whereas, under-predicted flow index (7\%). The MRPR values for thermal properties indicate that models have over-predicted the thermal properties in the range of $0.6 \%$ to $1 \%$. The bias factor values for flow and thermal properties are close to one indicating that there is no systemic bias. Accuracy factors ranged from 1.02 to 1.12 . A value of 1.02 suggests that deviation of predicted value from experimental value is about $2 \%$.

\section{Conclusions}

This paper presents the measured flow and thermal properties of stevia powder at a range of moisture contents. The angle of internal friction measured at different moisture contents were more than $30^{\circ}$ for stevia powder indicating that stevia powder cannot be discharged from silos and bins by gravity. Based on the measured values of flow index, stevia powder can be classified as cohesive/poor flowing material. The study showed a positive correlation between thermal conductivity and moisture content. A positive correlation was also observed between thermal diffusivity and moisture content. However, moisture content had no 
significant effect on specific heat for the measured moisture range of 5 to $26 \%$. The data extends the range of knowledge of flow and thermal properties of stevia powder to moisture contents that have not previously been reported.

\section{Acknowledgements}

This work was supported by the Georgia Department of Agriculture, Specialty Plant Block Grant, through Grant 334223, and by the U.S. Department of Education, through Grant DoE P382G090013 to Fort Valley State University.

\section{References}

ASABE Standards. 2011. S358.2: Moisture Measurement-Forages. In American Society of Agricultural and Biological Engineers Standards. St. Joseph, MI: ASABE, p. 389. ISBN 1892769786.

BOŽIKOVÁ, M. - HLAVÁČ, P. - VOZÁROVÁ, V. - BELÁŇ, L. 2015. Experimental determination of soft wheat flour thermal parameters. In Acta Technologica Agriculturae, vol. 18, no. 1, pp. 6-9.

BRANDLE, J. E. - TELMER, P. G. 2007. Steviol glycoside biosynthesis. In Photochemistry, vol. 68, pp. 1855-1863.

CARSON, J. K. 2015. Thermal conductivity measurement and prediction of particulate foods. In International Journal of Food Properties, vol. 18, no. 12, pp. 2840-2849.

DE CAMPOS, M. M. - DO CARMO FERREIRA, M. 2013. A comparative analysis of the flow properties between two alumina-based dry powders. In Advances in Materials Science and Engineering, vol. 2013, article id. 519846, pp. 1-7.

FASINA, O. O. 2006. Flow and physical properties of switchgrass, peanut hull, and poultry litter. In Transactions of the American Society of Agricultural and Biological Engineers, vol. 49, no. 3, pp. 721-728.

FITZPATRICK, J. J. - BARRINGER, S. A. - IQBAL, T. 2004. flow property measurement of food powders and sensitivity of Jenike's hopper design methodology to the measured values. In Journal of Food Engineering, vol. 61, no. 3, pp. 399-405.

FLAVIA, V. S. - ROSANGELA, B. - MARCOS, G. C. - ANDRADE, N. - NADIA, R. C. - FERNANDES, M. - MIRIAHESPANHOL, M R. - ALVARO, A. A. - SUZANA, L. R. 2007. Purification process of stevioside using zeolites and membranes. In International Journal of Chemical Reactor Engineering, vol. 5, no. 1, pp. 1-6.

GASMALLA, M. A. A. - YANG, R. - HUA, X. 2014. Stevia rebaudiana Bertoni: An alternative sugar replacer and its application in food industry. In Food Engineering Reviews, vol. 6, pp. 150-162.

GOSUKONDA, R. - MAHAPATRA, A. K. - EKEFRE, D. E. - LATIMORE, M. JR. 2017. Prediction of thermal properties of sweet sorghum bagasse as a function of moisture content using artificial neural networks and regression models. In Acta Technologica Agriculturae, vol. 20, no. 2, pp. 29-35.
HUANG, L. - LIU, L. 2009. Simultaneous Determination of Thermal Conductivity and Thermal Diffusivity of Food and Agricultural Materials Using a Transient Plane-source Method. In Journal of Food Engineering, vol. 95, no. 1, pp. 179-185.

KAMATH, S. - PURI, V. M. - MANBECK, H. B. - HOGG, R. 1993. Flow properties of powders using four tests: measurement, comparison and assessment. In Powder Technology, vol. 76, no. 3, pp. 277-289. KOSTAROPOULOS, A. E. - SARAVACOS, G. D. 1997. Thermal diffusivity of granular and porous foods at low moisture content. In Journal of Food Engineering, vol. 33, no. 1, pp. 101-109.

JEYAMKONDAN, S. - JAYAS, D. S. - HOLLEY, R. A. 2001. Microbial modeling with artificial neural networks. In International Journal of Food Microbiology, vol. 64, no. 3, pp. 343-354.

LASEKAN, O. - NAIDU, R. M. 2013. Changes in the volatile constituents of the leaves of Stevia rebaudiana Bertoni caused by different drying procedures. In Journal Food, Agriculture and Environment, vol. 11, no. 3, pp. 190-194.

LEMUS-MONDACA, R. - VEGA-GALVEZ, A. - ZURA-BRAVO, L. - AHHEN, K. 2012. Stevia rebaudiana Bertoni, source of a high-potency natural sweetener. A comprehensive review on the biochemical, nutritional and functional aspects. In Food Chemistry, vol. 132, no. 1, pp. 1121-1132.

MAHAPATRA, A. K. - EKEFRE, D. E. - PATTANAIK, N. K. - JENA, U. WILLIAMS, A. L. - LATIMORE, M. Jr. 2017.Thermal properties of sweet sorghum bagasse as a function of moisture content. In Agricultural Engineering International: CIGR Journal, vol. 19, no. 4, pp. 108-113. MAHAPATRA, A. K. - LAN, Y. - HARRIS, D. L. 2011. Influence of moisture content and temperature on thermal conductivity and thermal diffusivity of rice flours. In International Journal of Food Properties, vol. 14, no. 3, pp. 675-683.

MAHAPATRA, A. K. - MELTON, S. L. - ISANG, E. M. 2013. Effect of moisture content on thermal properties of cowpea flours. In Agricultural Engineering International: CIGR Journal, vol. 15, no. 2, pp. 251-255.

PÓL, J. - HOHNOVÁ, B. - HYOTYLÄINEN, T. 2007. Characterization of Stevia rebaudiana by comprehensive two-dimensional liquid chromatography time-of-flight mass spectrometry. In Journal of Chromatography A, vol. 1150, no. 1-2, pp. 85-92.

PURI, V. M. 2002. Characterizing powder flowability. In Chemical Processing, vol. 65, no. 1, pp. 39-42.

RAIGAR, R. K. - MISHRA, H. N. 2015. Effect of moisture content and particle sizes on physical and thermal properties of roasted Bengal gram flour. In Journal of Food Processing and Preservation, vol. 39, pp. 1839-1844.

SLETTENGREN, K. - XANTHAKIS, E. - AHRNE, L. - WINDHAB, E. J. 2016. Flow properties of spices measured with Powder Flow Tester and Ring Shear Tester-XS. In International Journal of Food Properties, vol. 19, no. 7, pp. 1475-1482. 